\title{
Known and Unknown Weaknesses in Software Animated Demonstrations (Screencasts): A Study in Self-Paced Learning Settings
}

\author{
George Palaigeorgiou, \\ Department of Computer \& \\ Communication Engineering, \\ University of Thessaly, \\ Volos, Greece
}

gpalegeo@gmail.com

\author{
Theofanis Despotakis, \\ Computer Science Department, \\ Aristotle University of \\ Thessaloniki, \\ Thessaloniki, Greece
}

tdespota@gmail.com

\section{Executive Summary}

Learning about computers continues to be regarded as a rather informal and complex landscape dominated by individual exploratory and opportunistic approaches, even for students and instructors in Computer Science Departments. During the last two decades, software animated demonstrations (SADs), also known as screencasts, have attracted particular attention as a promising platform for the struggling computer users. However, their anticipated ground-breaking success has not yet been verified, while research results have been both limited and inconsistent. In this study, we explore the deficiencies of SADs in a self-paced learning environment for computer science students, with a view to pinpointing design priorities for the enhancement of their learning value. An application containing 161 SADs was developed and distributed to thirty students who participated in three interviews during a period of two months and gave consent to usage logging for research purposes. The results of our study showed that, although computer science students recognized SADs as persuasive and intriguing media, their exploitation of SADs was not a straightforward matter. Problems reported included ineffective support during practice, the absence of encoding opportunities, low exploratory qualities and limited navigation opportunities. Other difficulties concerned pacing conflicts, incomplete self-descriptions, the inconvenience of the required environmental settings, and unexpected exposure to explicit time requirements, all of which challenged students' previously-acquired learning strategies. Students negotiated their study model right through until their last usage sessions because SADs were interruptive and did not encourage or facilitate any specific practice model. Even though these problems were confronted by all students, a significant percentage of them watched the videos in their entirety, developed tricks to overcome SADs disadvantages, overcame the novelty effect, and extracted most of their value. This is a promising sign

Material published as part of this publication, either on-line or in print, is copyrighted by the Informing Science Institute. Permission to make digital or paper copy of part or all of these works for personal or classroom use is granted without fee provided that the copies are not made or distributed for profit or commercial advantage AND that copies 1) bear this notice in full and 2) give the full citation on the first page. It is permissible to abstract these works so long as credit is given. To copy in all other cases or to republish or to post on a server or to redistribute to lists requires specific permission and payment of a fee. Contact Publisher@InformingScience.org to request redistribution permission. for the future diffusion of SADs in the acquiring of software skills in information technology education and underlines the need to enhance their form and the affordances provided.

Keywords: screencasts, animated demonstrations, video presentations, software training, multimedia learning, vicarious learning. 


\section{Introduction}

The ever-growing importance of computer literacy has ensured the continuity of political and scientific interest in computer learning media and environments for over 30 years. Although humancomputer interaction research has strived to facilitate the acquisition of software skills, firstly through the design and exploitation of interfaces that have clear intentions, anticipated semiotics, direct manipulations, real world metaphors, and various other exciting qualities (Shneiderman \& Plaisant, 2005) and, secondly, by designating 'learnability' as one of the most fundamental usability attributes of software applications (Grossman, Fitzmaurice \& Attar, 2009), most idiosyncratic problems related to computer learning remain unsolved. The "paradox of the active user" (Carroll \& Rosson, 1987; Fu \& Gray, 2004) endures since users persist in realizing tasks in an inefficient way even when demonstrably more efficient procedures exist. The occasional, rather than causal or premeditated, character of computer learning (Phelps, Hase, \& Ellis, 2005), as well as various factors such as the impossibility of complete coverage of the computer knowledge domain, the inevitability of knowledge obsolescence (Eisenberg \& Fischer, 1993) and the prevalence of unsupported exploratory learning from early on (Carroll \& Rosson, 1987), constitute a complex and original learning ecology (Barron, 2004). Computer learning is a complex task that puts a tremendous burden on all computer users, experienced or not (Kiesler, Zdaniuk, Lundmark, \& Kraut, 2000), and results in a multiplicity of 'frustrating experiences' and extensive time losses (Lazar, Jones \& Shneiderman, 2006). Regardless of the multibillion investments in schools, universities, and corporate training activities (Corrall, 2008; Gupta \& Bostrom, 2006), computer learning continues to be viewed as a personal landscape dominated by individual exploratory approaches, even for students and instructors of Computer Science Departments.

Software animated demonstrations (SADs), which were developed in the early 1990s and which more recently have come to be known as 'screencasts', have generated new interest as a promising platform for computer users. Many commercial authoring tools, such as TechSmith Camtasia $(\mathrm{C}$ and Adobe Captivate $($, and free authoring tools, such as Articulate ScreenR $\mathbb{C}$, TechSmith Jing $\bigcirc$ and Wink Screen Recorder $\odot$ have been made available, while a new trend towards sharing screencasts in specially configured web 2.0 platforms (such as www.jingproject.com) or generic user generated video sites (such as www.youtube.com), have also started to gain momentum. SADs, in their primitive form, reproduce a screen-captured usage scenario of a software application. Their definition is usually differentiated on the basis of the presumed presenter or the scenario contents. In most cases, SADs resemble watching an instructor, an expert, a ghost user, a colleague, or even a student providing worked-out examples of software utilization.

From a factual point of view, SADs constitute a unique tool for e-learning design, especially for Computer Science instructors, since they promote an easy and affordable way of producing multimedia instructional material that is authentic, situated, and motivating and can be exploited in various educational settings (in the classroom, self-paced, collaboratively, etc.) unlike other kinds of multimedia resources. Instructors, whose role in educational technology adoption has long been underestimated, desperately seek an accessible technology that enables the quick creation/development of software tutorials and that allows them to update the learning material frequently in order to keep up with the pace of software evolution. SADs production, with the use of the last generation of screencasting tools, requires almost a time-frame similar to the one needed for preparing a class demonstration plus the time required for recording it, or, in essence, realizing it for once. The capturing of users' actions on the entire screen or in a specific application window is automatic, while the videos are typically extracted in formats which are compatible with the majority of media players and browsers. More importantly, the editing process of the demonstration, if needed, inherits characteristics from widespread video and word processing software making the familiarization phase with the authoring features short and effortless. These elements may be more determinative factors in SADs uptake than the comparative learning effi- 
ciency advantages of other technologies and media which require more effort in order to produce educational products.

The recent growth of SADs as a vehicle for documentation, help, and training on new software systems or games (Shneiderman \& Plaisant, 2005) is an indication of users' and designers' willingness to use SADs. Although the subject of study for many years, they still seem to be in their infancy since there is a lack of established design guidelines, while prompts and practical tips offered (e.g. Educause Learning Initiative, 2006; Kroski, 2009; Oud, 2009; Plaisant \& Shneiderman, 2005) usually seem like superficial remedies for our inconclusive understanding. Opportunities to revolutionize their form and learning effectiveness are tremendous since many development paths, such as the exploitation of cinematic techniques or the adaptive presentation of the learning video-content, have not yet been investigated. However, their prevalent and easy-toproduce form has to be assessed. In this paper, we will explore typical SADs integration in ordinary real self-paced learning settings of computer science students, in order to validate and enhance previous research results and extract design directions.

\section{Literature Review}

SADs are praised mainly for their authenticity (de Souza \& Dyson, 2008; Despotakis, Palaigeorgiou, \& Tsoukalas, 2007; Harrison, 1995; Palmiter, 1993; Spannagel, Girwidz, Lothe, Zendler, \& Schroeder, 2008), since they show transparently and directly the objects manipulated, their transitions and transformations, as well as position and timing information, focus orientation and mouse movements. As students have commented, SADs convey information that is only tacitly communicated by other knowledge sources (Despotakis et al., 2007), facilitating the development of a better mental model of human-interface interactions. Learners perceived them as more explicit and comfortable to use than static versions of instructions (de Souza \& Dyson, 2008; Despotakis et al., 2007; Ertelt, 2007; Palmiter \& Elkerton, 1993) and compared them with one-toone instruction, with the advantage of more control and autonomy. They have even claimed that SADs create an 'agency' effect, namely, the impression of self-executing the task presented (Despotakis et al., 2007). The primary learning value of SAD is the elimination of the 'referential step' (Just \& Carpenter, 1987) required for the comprehension of textual instructions. Hence, initial learning is fast since students do not spend time interpreting the steps (Palmiter \& Elkerton, 1993 ) and avoid the laborious trial-and-error process. SADs also overcome the intra-presentation split attention effect (Lowe, 2003) as the modeled behavior is shown in the same medium as the desired behavior and, hence, unproductive cognitive load while skipping between different sources (e.g. from books to the computer) is circumvented. Moreover, SAD monitoring constitutes a vicarious experience, since a user learns by observing the desired behavior of an expert, and, consequently, it aids learners with low self-efficacy in exploring the demonstrated behaviors, and in achieving similar benefits, as Social Theory suggests (Bandura, 2001; Compeau \& Higgins, 1995; Margolis, 2005). All in all, most users appear to be very willing to use SADs (Despotakis et al., 2007; Harrison, 1995; Palmiter \& Elkerton, 1991; Pane, Corbett, \& John, 1996; Payne, Chesworth, \& Hill, 1992; Shneiderman \& Plaisant, 2005) and appreciate their motivational potential (Atlas, Cornett, Lane, \& Napier, 1997; Despotakis et al., 2007).

Although the widespread assumption about SADs is that they facilitate comprehension and memory, research results are less affirmative. SADs, and animated demonstrations in general, are not a panacea and therefore are not often used (Pane et al., 1996; Tversky, Morrison, \& Betrancourt, 2002). Almost all studies have shown that SADs are just as effective as or more effective than textual descriptions in initial acquisition of software skills and, usually, offer quicker and more accurate immediate demonstration of procedures (Harrison, 1995; Kerr \& Payne, 1994; Lipps, Trafton, \& Gray, 1998; Spannagel et al., 2008; Waterson \& O’Malley, 1992). However, questions have been raised about the long-term retention and transferability of knowledge, since substantial 
deterioration in training effects was indicated by students' performance in post-tests (Kerr \& Payne, 1994; Palmiter, 1993; Palmiter \& Elkerton, 1993). Subsequent studies have ascertained that retention remains the same for tasks which have been demonstrated and deficiencies may only exist when the tasks examined are different from the ones studied and where deeper understanding is required (Harrison, 1995; Lipps et al., 1998). However, even these deficiencies have been challenged in newer studies (Ertel, 2007; Lewis \& Barron, 2009).

The theoretical underpinnings of SADs critique have concentrated mainly on the 'mimicry model,' according to which the learners try to memorize the steps presented and copy them to the application environment without understanding the task (Atlas et al., 1997; Palmiter \& Elkerton, 1993). Essentially, SADs may induce a surface processing strategy, and the resulting lack of cognitive processing and active inferring can reduce retention and transferral skills, as what has been evident is the reverse relationship (Harrison, 1995; Palmiter \& Elkerton, 1991). Hence, the authenticity of SADs cannot be considered as a guarantee of their effectiveness and, furthermore, might even create only the illusion of capability (Despotakis et al., 2007). The continuous form of the presentation also limits the control of the learning pace and the variety of learning strategies available (de Souza \& Dyson, 2008; Ertelt, 2007; Haas, Brown, Cao, \& Wilbur, 2005). Additionally, researchers have claimed that SADs may distract users from concentrating on key issues and have fundamental usability flaws (Despotakis et al., 2007). It is also plausible that learners perceive SADs as an easy way of learning, and this might make them less activated and engaged (Ertelt, Renkl, \& Spada, 2006; Palmiter \& Elkerton, 1991), undermining learning outcomes.

More recent studies support the view that learning effectiveness through SADs is highly dependent on different design characteristics, which can have considerable influence on learning even in the medium- and long-term (de Souza \& Dyson, 2008; Ertelt, 2007; Spannagel et al., 2008).

SADs research has tended to focus mainly on segmentation, presentation modality, practice strategy, learning task particularities, and users' learning styles and prior experience.

Segmentation is considered to improve learning efficiency given that the parts of the task can be studied separately and students can take over control of their learning pace, however, no conclusive results exist. Harrison (1995) attributed the maintenance of performance over time to segmentation while Ertelt (2007), after examining different forms of segmentation, concluded that under specific conditions, labeling segments fostered declarative knowledge while self-pacing in the form of a push-button had a significantly positive effect on problem-solving performance. Waterson and O'Malley (1992) indicated that the type of interface to be learned affects learning results with SADs, while de Souza and Dyson (2008) reviewed the task characteristics that suit SADs:

- when the task involves continuous changes not easily inferred by the user,

- when it is based on direct manipulation interface,

- when it is clearly segmented into procedural steps, and,

- when it will be practiced immediately after watching SADs.

An equally important role has been attributed to learners' prior experience of the task in hand. In general, SADs have been identified as more suitable for novices since the amount of cognitive processing is reduced and immediate practice skills are easily acquired. However, learners have challenged SADs capacity to present complex skills that interweave with deep domain knowledge (Despotakis et al., 2007). They have also claimed that experts would have difficulty in overcoming the pacing deficiencies and the redundant information presented, as well as their exploration deficiencies (Despotakis et al., 2007). These notions are validated also by the 'expertise reversal effect' (Kalyuga, Ayres, Chandler, \& Sweller, 2003), according to which methods adequate for novices lose their effectiveness or even have a negative impact on experienced learners. 
Of course, the results presented here are focused on studies examining SADs, while relevant hypotheses could also be derived from two interconnected theoretical frameworks of high relevance: a) multimedia learning, and, b) vicarious learning. The cognitive theory of multimedia learning (Mayer, 2005; Mayer \& Moreno, 2003; Paas, Renkl, \& Sweller, 2004; van Merriënboer \& Sweller, 2005) tries to adapt the structure of information, and the way it is presented, to human cognitive architecture, with the goal of developing design guidelines that enable learners to use their full cognitive capacity. In this context, multimedia theory has studied various parameters that influence the effectiveness of multimedia learning presentations which are similar to those mentioned concerning SADs, such as split attention, modality, segmentation, pre-training, signaling, and temporal contiguity effects (Mayer \& Moreno, 2003). Animated demonstrations bear a close resemblance to SADs and a recent meta-analysis comparing dynamic and static visualizations (Höffler \& Leutner, 2007) provided analytic evidence as to their learning value. Design principles for animated demonstrations elaborate on quite similar design issues (Plass, Homer, \& Hayward, 2009; Wouters, Paas, \& van Merriënboer, 2008) and, therefore, constitute a relevant source of information for SADs.

SADs, as previously stated, are a form of vicarious (observational) learning since they promote learning by observing, and replicating behavior executed by others. Hence, social cognitive theory (Bandura, 1986, 2001) also provides an extensive framework for examining their characteristics. It describes relevant component processes, such as attention, retention, production, and motivation to continue using them (Yi \& Davis, 2001), as well as analyzes the results of observational learning in terms of changes in performance, the acquisition of new operants, the acquisition of higher-order operants, the acquisition of conditioned reinforcement by observation and the acquisition of observational learning repertoires (Greer, Dudek-Singer, \& Gautreaux, 2006). It also examines approaches to achieving improvement, such as practice (Yi \& Davis, 2001), retention enhancement (Yi \& Davis, 2003), symbolic mental rehearsal (Davis \& Yi, 2004) and enactive learning (Gupta \& Bostrom, 2006), all of which have been exploited in the evaluation of SADs from the behavioral modeling perspective.

Hence, SADs constitute the combined materialization of several distinct research streams, and their assessment and advancement has just begun, since its media form is well-suited to the aesthetics and authoring conveniences sought in the next wave of e-learning applications.

\section{Research Goals}

It is commonly believed that the anticipated ground-breaking success of SADs has not yet been verified (Ertelt, 2007), while research results remain limited and inconsistent. It is true that the sheer variety of forms tested and the consequent contradictory results have hindered the development of a coherent set of practical guidelines. In addition, most of the studies have been conducted in laboratory settings, rendering their conclusions concerning pragmatic software learning questionable; computer learning should not be oversimplified since it evolves through multiple independent and occasional episodes distributed across the contexts of home, work, and community (Barron, 2004), and also evokes changes in attitudes, values, and beliefs. This is even more intense for computer science students. When evaluating a learning platform, we should not overlook the fact that continuous use is a form of design (Allen, 1993) and, from this point of view, the learning curve, preferences, expectations, and desires are equally important factors contributing to effectiveness in long-lasting usage (de Souza \& Dyson, 2008), while a reciprocal interaction evolves among them.

In this paper, we aim at exploring the deficiencies of SADs, in a self-tailored rather than in an imposed learning environment. This will be achieved by exploring the following questions:

- Which of the SAD characteristics impede learning? 
- What are the students' attitudes toward SADs in the different stages of the learning curve? Which are the learners' study models?

- Which tools did not meet learners' needs? Which were the affordances, namely, the perceivable action possibilities, that were absent according to learners?

\section{Methodology}

In order to achieve the research aims, suitable subject-matter that matched the sample's learning interests had to be selected, since motivation influences all dimensions of observational computer learning processes (Yi \& Davis, 2003). An informal investigation was conducted during two lectures on an undergraduate course in a Computer Science department, and Adobe Flash $\mathbb{C}$ proved most popular. The students' proposal was deemed satisfactory as this particular application consists of unfamiliar interaction objects which would undermine any attempt to use unsystematic explorative strategies and also has the proper task characteristics for SADs (de Souza \& Dyson, 2008). An educational application, containing 161 animated demonstrations of a duration varying between 22 seconds and 20 minutes 3 seconds and with an average of 7 minutes, was developed. SADs covered topics suitable both for novices and experienced users of the particular software. Each SAD included auditory descriptions from a teacher, explaining concisely the utility of a particular function and demonstrating the steps toward execution, in the form of worked examples in accordance with basic multimedia learning guidelines (Mayer, 2005). No extraneous material was included, the language used in the descriptions was informal, and proposals for practice were included in the descriptions as scaffolding to support and activate learners. No semiotic particularities or cues were included in the presentation so as to permit the investigation of SADs in their primitive form, which is the most widespread and effortlessly authored. Users had full control over the video pace presented, while, at the same time, there were no constraints in SADs selection. A thematic tree was offered as a means of navigation among SADs, which retained and presented history data (visited, last visited, etc.).

After the development of the educational application, an announcement was made concerning an activity in which students could access and acquire the application freely, together with some other educational resources, while they should participate in three interviews over a two-month period and give consent to data logging for research purposes. Thirty students in the third or fourth year of their undergraduate studies were registered, of whom 18 were male and 12 female, with no or limited experience of the specific software application. Registered students were, in addition, given free e-books and a list of the best web-training resources. This was done in order to emulate a more realistic learning ecology in which the use of SADs is a possibility and not a necessity. There were no learning objectives and no recommendations as regards using the educational application. Students could use an evaluation copy of the application for practice purposes.

The exploratory study was based on quantitative and qualitative data monitored over a period of two months. Quantitative data were derived from tracing the usage periods of the students, the sequence of the SADs selected, and the time dedicated to each one, with the help of the WebInspector (Despotakis, Palaigeorgiou, \& Tsoukalas, 2003). Qualitative data were collected from three consecutive semi-structured interviews, which were conducted with each student on the 15 th, the 30th, and the 60th day (approximately) of the study. The first two were phone-based, relatively short (15-20 minutes), and focused on learning effectiveness, motivation, intensity of use, and the evolution of the study model. In the last interview, students were required to export and bring the WebInspector log file with them. This interview was extended, with a mean duration of 80 minutes, and it re-examined the same issues, but also asked the students to comment reflectively on their usage statistics (e.g., time dedicated to different sessions, learning paths, SADs not studied, etc.). Students in the last interview also completed a short questionnaire consisting of seven 5-point Likert scales that quantified their perceptions and beliefs about SADs 
(same as in Despotakis et al., 2007). Throughout all the interviews, students were encouraged to propose ideas and identify problems concerning SADs and the corresponding learning environment.

\section{Results}

\section{Usage}

Four students did not continue to use the educational application after the first interview and a fifth student went no further than the second interview stage. Twenty-six students participated in the final interview and twenty-four of these provided us with their log files. The general usage statistics from the log files are presented in Table 1. We discerned three different levels of application usage. The first group of students used the application for little less than an hour on average on a few days. The second group explored the application for 6 to 7 days and for about 6-7 hours and studied a significant number of animated demonstrations. The last group, which consisted of 8 students, studied the whole learning material extensively for 12-13 days while they explored the application as a whole for 15-16 hours on average. Therefore, the participants demonstrated a balanced set of reactions towards software animated demonstrations from the usage and acceptance angle and our results represent a variety of views.

Table 1: Screencasts Usage

\begin{tabular}{|l|c|c|c|c|c|c|}
\hline & Participants & Sessions & \multicolumn{1}{l|}{ Days } & Time (min) & SADs viewed & SADs viewed/ session \\
\hline Group A & 7 & 6,14 & 3,71 & 65 & 24 & 5,3 \\
Group B & 9 & 8,2 & 6,2 & 352 & 67,5 & 10 \\
Group C & 8 & 19,6 & 12,5 & 1086 & 138 & 8,1 \\
\hline Total & 24 & 274 & 182 & 12313 & 1896 & \\
\hline
\end{tabular}

\section{Positive Attitudes towards SADs}

In all the inquiry stages, the students confirmed the appealing and authentic nature of SADs and characterized them as "interesting", "enjoyable", "live", "helpful", "comfortable", "relaxed", and "intriguing". Students claimed that SADs increased their application-specific confidence even without practicing the tasks demonstrated. In the last interview, many of them specified that SADs have a significant advantage in that learning is less impersonal and there is a sense of social presence: "Compared to books, SADs are more personal, pleasant, and more 'humanized' since you believe that someone is showing you what to do." Once again, they compared learning with SADs with that of one-to-one teaching and underlined that SAD analytic descriptions were enough to ensure the precise and successful reproduction of the procedural steps presented. SADs were evaluated as more efficient than internet resources because they averted the possibility of feeling lost and were also considered to be more attractive than e-books.

The majority of the students stated that they could easily reproduce procedures with SADs $(\mathrm{M}=4,79, \mathrm{SD}=0,41)$, they would prefer to learn about the functionality of new computer applications using SADs $(\mathrm{M}=4,71, \mathrm{SD}=0,55)$, they were satisfied with the SADs selected and watched $(\mathrm{M}=4,38, \mathrm{SD}=0,58)$, they would recommend SADs to their friends who want to learn about new software $(\mathrm{M}=4,63, \mathrm{SD}=0,58)$, and they learned with $\mathrm{SADs}$ in a more efficient way compared to other means (e.g., e-books, web pages, etc.) $(\mathrm{M}=3,96, \mathrm{SD}=0,69)$. Discrepancies between the responses of the three groups of participants were detected only in their views about whether SADs make computer learning faster (Mgroup1=3,29, Mgroup2=3,89, Mgroup3=4,25). Students in the group of limited usage of the educational application did not attribute time efficiency to SADs and that was one of the reasons for not continuing with their use of the application. 


\section{SADs Impediments}

In general, there was surprising contradiction amongst students' general assessments of SADs and in their comments about their usage sessions in the last interview. The overwhelming majority of students provided positive evaluations concerning tool utility, but pinpointed many difficulties which were confronted in the self-paced learning settings. We organized students' issues into four groupings: 1) usability flaws, 2) study model evolution, 3) psychological side-effects, and 4) learning conditions. It is important to note that most of the deficiencies mentioned later are not derived from authors' design decisions but are inherent in the way SADs are authored and delivered currently, at least.

\section{Usability flaws}

\section{Ineffective support during practice - A new form of split-attention effect}

As already mentioned, SADs have been praised for overcoming the split attention effect as the modeled behavior is shown in the same medium as the desired behavior and, hence, students are not required to transfer their attention between different media. However, in our study, two more significant sources of unproductive (extraneous) cognitive load were detected. The first one concerned the inability to practice the exemplary procedures while studying the material, since SADs usually occupy a large proportion of the screen, rendering it unfeasible to monitor both the tutorial and the software application screen simultaneously. Students were disturbed by the need to continuously swap between the two windows, by the inability to observe and compare both at the same time, and by the need to pause, play, and replay the videos. The second complaint was related to the form of support that SADs offer when students practice. Typical SADs do not present instructions in a clear, concise way, neither do they provide an alternative textual representation of their contents, forcing learners to spend time watching short parts of videos in order to remember a menu item or identify details for the procedural steps. Consequently, instead of scaffolding learners when they perform the tasks and decreasing intrinsic cognitive load, SADs distract learners:

"It was annoying that when I tried to apply some functions, if I failed, I had to watch the whole video again."

"When I started practicing, I initially watched them up to a point, I paused the video and then I repeated the same actions in flash. Switching between applications was tiresome. Later, I started to see a number of videos and then explored the application. "

The problem was more intense in lengthy videos where memorization was unavoidably poor and knowledge was presented in the context of more complex case studies. Students, in the last interview, asked for short videos in order either to recall them more easily or to seek the required information more effectively, and that was their proposed form of segmentation.

"I do not like the 20-minute videos because I cannot watch them and then explore the application; I have to stop, then experiment and then continue, then stop...It is very uncomfortable to combine practice with long videos."

"I cut the lengthy videos into parts and I study them accordingly. I could not remember anything after such (long) videos. "

Since students perceived SADs as being an inefficient platform for supporting their practice, they also evaluated them negatively concerning their later referencing uses. Some students tried to overcome SADs weaknesses by taking notes on paper where they wrote down abbreviations about interesting, significant or complex tasks. Essentially, they created a temporary medium which allowed them to avoid the split-attention effect evoked by switching windows and enabled 
them to re-use those notes later without having to open the educational application. Some students kept excessive notes on each video and essentially replaced the video with short textual descriptions for later referencing purposes. An interesting approach to combining SADs and practice was also that of listening to the audio only and the consequent execution of the instructions rehearsed.

"I started to listen to the video while practicing because it was difficult to continuously switch between the two applications."

"Each time, I wrote down the steps required for each procedure. I watched the video, I created notes and then I took advantage of them in the application. I wrote down notes for each video separately. I wanted to be able to see those notes later. "

\section{Self-description}

SADs, in their current form, do not offer sufficient description of their contents and are innately non-explorative. Titles, descriptions, or summaries cannot reveal the details of the learning content. Searching is based on metadata attributes and depends on the remembering of the screenshots and their context. Students argued that locating the presentation of a specific operation, required an exhaustive exploration of multiple SADs and the paradox of 'seeing to select and not selecting to see' was detected (Despotakis et al., 2007). Students exploited books, web search, and the help system when seeking something specific.

"The basic disadvantage of the videos is the limited searching capabilities. For example, when I learn a programming language and I want to remember the syntax of a command, I have to search in a pdf or something similar. You need to combine pdfs and text with video. "

"I tried to step up my pace by selecting not to watch some parts which I thought I knew; however, that proved difficult because I also did not watch important things which I needed later. I couldn't understand a priori the exact contents of the videos. "'

\section{Inherent pacing impediments}

Video-based presentations are inherently characterized by the predetermined pace of information presentation and the inflexibility of adapting their contents to different requirements and different types of viewers. Students indicated this disadvantage several times either by claiming that the presentation was too fast, exceeding their ability to assimilate the content presented, or too slow, boring and verbose when operations were already familiar (Despotakis et al., 2007; Haas et al., 2005). The inflexibility of pacing places heavy demands on students who have to prioritize and integrate the incoming information according to their learning objectives and in synchronization with the rate of the presentation. As also applies in animation-based learning, learners did not feel in control of the pace and of the study details (Mayer, 2005; Tversky et al., 2002), despite having at their disposal the typical video controls; moreover, they were confronted by the designers' hypothesis concerning beginners and those hypotheses were diffused throughout the complete set of videos, a particularly annoying situation in the case of the more experienced computer users in our sample.

Furthermore, SADs were criticized for their representativeness, which although it was the most desired and appealing element at the beginning of the learning curve, eventually became excessive. SADs offer more information than the other means but do that far more times than necessary. The overcoming of the 'referential step' is transformed into an "explanatory exaggeration" and students have to be patient and try continuously to identify if there is something new or unknown or when the unfamiliar information and unknown steps start to be presented.

"Afterwards, I started to feel tired...several items were repeated many times."

"In the beginning I was very satisfied but then the repetition of details became tedious." 


\section{Absence of hypertext affordances}

Students mentioned that the absence of hypertext affordances was a significant drawback in achieving the desired navigational flexibility and was also in dissonance with their prior exploratory learning style as exercised in hypertext. Students criticized the inability to move to specific labeled points in the videos and the absence of links inside the videos that provide the opportunity to contextualize learning.

"I wondered myself where the links were and how I could see relevant steps in different contexts."

\section{Study model evolution: Not easily converging}

Since students had no experience with SADs, they had to negotiate their study model in order to match SAD particularities to their needs, habits, and learning conditions. This task proved tiresome, and it was interesting that most of the students, in the last interview, underlined that if they were to start studying SADs from the beginning again, they would follow a different strategy from the one they had selected. Hence, SADs are not a straightforward medium to assimilate and incorporate in everyday learning practice.

"If I were to start again, I would watch all the videos sequentially and I would try to do everything that is presented alone."

"If I started again, I wouldn't watch the videos sequentially. I would choose to study specific videos and I would be more focused on the task in hand. "

Compulsion to follow an ineffective initial study model: Feeling insecure about skipping content

The appealing characteristics of SADs immediately attracted most learners' engagement with the application and made them watch all the video contents without taking into consideration their prior knowledge and experience. This predisposition was transformed into self-compulsion for a long period of time in order not to miss valuable information. Students felt insecure about skipping content, and they were unable to surmount this insecurity despite their realization of the inefficiency of the study model.

"It is tiring to watch entire videos while you do not feel that they offer you anything."

"I was afraid to fast-forward the video; I was afraid of skipping the details."

\section{Three different final study models}

We did not detect a prevalent final study model, but, rather, different ones. In general, students, after the first phase transformed their study model to one of the three following alternatives - similar to general computer learning strategies detected in other studies, such as in Rieman (1996):

a) They started to select and watch SADs related to their goals or learning interests and dropped the systematic exploration of all contents. Watching SADs was followed by accomplishing the task in hand and, according to students, this task-oriented approach improved their study efficiency significantly.

"Now, I have changed my study model. In the beginning, I watched all videos sequentially and I worked concurrently in flash in order to develop my skills. I reached section 7 or 8, and then I realized that this strategy is tedious in the long-term and also I could not recall some things...Now I load the educational application if I need some kind of help."

"Now, my selection depends on whether the title interests me. The sequential way is far too timeconsuming. " 
b) Several students acknowledged the negative effect of the mimicry model and claimed that SADs provoked illusions about skills, since, seeing a video was perceived initially as equating with learning its contents (Despotakis et al., 2007). Most of those students shifted their attention to developing a systematic combination of watching SADs and practicing-exploring the knowledge presented.

"In the beginning, I used the educational application more and I thought that I was acquiring the skills presented without practicing. I was a little bit confused about what I could do after watching a video."

"SADs present everything very transparently and vividly, but I do not know how good this is since we are transformed into rather passive viewers and we expect to 'consume' knowledge. I think that it is equally important to be activated and to search and explore alone. I practiced a lot alone after watching SADs. I was also afraid that I could be restricted to the 10 things presented and I would not look any further."

c) The "ineffective results of dynamic visualizations" (Lowe, 2003) were detected in the third group of people, who continued to view the SADs passively and regarded them as an informational broadcast which could give them an idea of the whys and wherefores of the software application. Learning the details was postponed until the implementation of a real task (Rieman, 1996). Those students claimed that SADs did not impose a significant metacognitive burden and that it constituted a form of 'edutainment'.

"In essence, I watched SADs without wasting time. For example, when I was downloading something, I watched one or two videos."

"It was like watching a TV educational show for an hour, and it was a very nice experience."

Although, this has also been described as the 'couch potato attitude' (Schwan \& Riempp, 2004), those students were just as satisfied as the ones who developed more practical skills. They considered that, in the information era, knowledge of possibilities is an aim of equal importance. There were no tools in the past offering such opportunities and SADs offered this extra value in the best way. Today, most commercial SADs serve this purpose exactly.

\section{Knowledge encoding opportunities}

Several students used note-taking on paper, not only to overcome the split-attention effect, but also to better understand, represent, and encode the knowledge discussed in the presentation. This was their countermeasure to the limited cognitive activation of monitoring and a way of becoming more active learners.

"In the beginning, I wrote down important things in order to learn them better."

"In the first videos I did not use notes, but when the videos started to present complex skills, I wrote them down in order to study and understand them."

Students, who did not monitor SADs passively, strived for knowledge-encoding opportunities, stimuli for symbolic coding, and learning activities that could increase their confidence and help them organize better the material presented. They also sought questionnaires and quizzes as a way of assessing their acquired skills in the real environment. They recognized that there was no meaningful learning without such activities and indirectly looked for opportunities for behavioral rehearsal and for other retention-enhancing interventions (Yi \& Davis, 2001, 2003).

"I would have been interested in questionnaires to assess my knowledge and understanding. It would have been an invaluable help in improving my learning."

"I would have liked to implement some tasks in the real environment and the application to check if I had completed the procedures successfully in order to evaluate my performance." 


\section{Psychological side-effects}

\section{Explicit time requirements: $A$ surprise}

Students were surprised to realize that SADs offered them quite a precise relation between establishing learning objectives and estimating minimum time requirements for achieving them. For the first time, in contrast with other means, students had an evaluation of the minimum time required to meet their aims and also felt the need to organize their study model, in terms of timescheduling their usage sessions for the long-term.

"When I start the application, I decide on the videos that I am going to study according to the time I have at my disposal."

"I decide initially what I will watch...videos have specific time requirements and you know de facto the time that you will dedicate when you study a section of videos."

The sense of the real magnitude of the learning task was sometimes discouraging since in other media there are no time constraints and study can be organized flexibly. However, the timescheduling also cultivated an environment of managed expectations that was more secure and predictable than searching on the internet or studying a book. This was a significant boost for students who studied the whole material.

\section{The monotony of one voice}

Students characterized the demonstrations from only one person for so many days as monotonous and boring and requested a greater variety of presenters.

"It was boring that one person spoke continuously. It was monotonous, maybe he could be changed sometimes."

"It is tiresome to listen to the same voice for so long; I took small breaks to relax."

\section{Learning conditions}

\section{Prior experience}

As expected, SADs were judged to be a more adequate tool for novices since all the usability flaws which were indicated are regarded as averting factors to experts who want to study the learning material flexibly. Students also questioned the value of SADs for the presenting of complex applications because the pacing conflict acquires an even more significant role, knowledge encoding opportunities do not exist, and practice is not supported adequately.

"SADs are suitable for a quick familiarization because they show things convincingly."

"I would recommend SADs to any novice without second thoughts. The application will not be useful for an expert since he can find the things he wants in different and more efficient ways. "

\section{Settings}

Students commented negatively on the particular conditions necessitated by multimedia learning since SADs usage in the lab or in the working environment required the use of earphones and total concentration and, hence, making very exacting demands within the computer learning ecology. They related SADs with "serious-formal learning" since they were unable to listen to music or browse the internet in tandem. SADs seemed to fall somewhere between the boundaries of informal self-controlled and more formal modes of learning, and this was something that took students by surprise initially. In addition, students reported physical discomfort (greater than reading a book) from eye-strain and the sitting posture taken continuously in front of the screen. This 
could be due to the fact that the SAD learning sessions followed on from what was already extensive computer usage for other purposes.

"Extensive computer use makes me feel tired, while the manual can be printed out and read anywhere."

"I usually close the application due to exhaustion because I am in front of a computer screen all day."

\section{Discussion}

SADs once more emerged as an attractive learning medium due to their authenticity, their multimedia affordances, and the feeling of personal contact that they engender. Computer science students regarded SADs as tools that initiate learning by providing a specific range of learning paths, with explicit goals and expectations, by means of a persuasive and intriguing presentation. After the two-month period of usage, the majority of students claimed that they would recommend SADs to their friends and characterized them as a very efficient way of learning compared to other means.

As already explained, the exploitation of SADs was not a straightforward activity and, in a way, students seemed to assess SADs as the best resource among a set of inconvenient and inadequate knowledge resources. They pinpointed several problems that hindered their learning and suggested that ineffective support during practice, as well as the absence of encoding opportunities, were the most significant drawbacks of SADs. Students negotiated their study model right through to their last sessions because SADs were interruptive and did not encourage or facilitate any specific practice model. At the same time, the low exploratory qualities derived from the limited navigation opportunities, the pacing conflict, the incomplete self-descriptions, the inconvenient but required environmental settings, the unexpected exposure to explicit time requirements, together with the initial superficial learning phase, challenged students' prior learning strategies. Even though those problems were confronted by all students and motivation was not controlled deliberately by the research setting during the two-month period, a significant number of them watched the videos in their entirety, developed tricks to overcome SAD disadvantages, acquired skills whether novices or more experienced, and surmounted the novelty effect in order to take maximum advantage of their value. This is a promising outcome for future diffusion of SADs in acquiring software skills in information technology education.

\section{Conclusion}

The study indicated that there is a great potential for improving SAD deficiencies, and new design directions should include:

- The provision of multiple views of the content that can enhance practice, as, for example, concise printable summaries of text, presentation modalities that allow the coexistence of SADs with the software under examination, such as audio or text-based guidelines in a small modal window, etc.

- The incorporation of the material in many modes (text, audio, video) and forms of organization in order to facilitate later referencing purposes and different types of learning objectives as detected in the three observed alternative study models. Exemplary services include the breadth-view of contents for students with the 'couch potato' attitude, or a task-oriented view of the contents for students exploiting the application with specific learning objectives in mind. 
- The creation of SADs players that enable the flexible re-structuring and management of video segments for students with different pacing requirements, as for example, a player showing only a sequence of print-screens of the actor's actions or a filtered view including only the actions not presented in videos previously studied by the student.

- The provision of extensive passive and active encoding opportunities, e.g., by offering note-taking and bookmarking opportunities, exercises and questionnaires, simulated practice with immediate feedback, abstract representations of the contents, etc.

- The incorporation of context-related hypervideo links within the video content, e.g., not only in the form of similar videos, but also in the context of the discrete action-steps as they are revealed in the video.

- The facilitation of the development of time-based learning plans, e.g., a support tool for creating study plans based on students' learning objectives and the time at their disposal.

- The participation of a variety of presenters with different approaches and a range of voices which could maintain students' interest.

- The cultivation of observational learning skills and the provision of studying guidelines in order to help students quickly develop an efficient study model and avoid common pitfalls such as the self-imposition of an ineffective initial study model.

While some of the points mentioned in this paper have already been identified in prior research, our results are significant since they indicate design priorities, verify, for the first time, some research claims in self-paced learning settings, and also recognize new challenges not previously mentioned. Interestingly, the technical environment of SADs deployment is changing rapidly since many users have in their disposition dual displays (enabling the partial avoidance of the split-attention effect), new screen capturing tools do not require the installation of desktop software but just the use of an internet browser (rendering the development of SADs even easier), and, finally, user generated video sites such as YouTube $\mathbb{C}$, TeacherTube $\subset$ make possible the sharing of screencasts with additional commenting features (adding a social dimension in their scope). Additionally, instructors seek the deployment of screencasts in various educational settings such as the computer lab where synchronization issues arise, or in order to create knowledge bases for supporting students at home, or even for capturing students' usage, identifying misconceptions, and providing feedback. All these observations necessitate the continuous study of SADs form, efficiency, and effectiveness in real usage conditions since video affordances are becoming much more familiar to students of computer science departments in their everyday learning practices. Certainly, SADs proved in this study that they can play a determining role in overcoming the costly paradox of the active user.

\section{References}

Allen, C. (1993). Reciprocal evolution as a strategy for integrating basic research, design, and studies of work practice. In D. Schuler \& A. Namioka (Eds.), Participatory design: Principles and practices (pp. 239-253). Lawrence Erlbaum Associates.

Atlas, R., Cornett, L., Lane, D. M., \& Napier, H. A. (1997). The use of animation in software training: Pitfalls and benefits. In M. A. Quinones \& A. Ehrenstein (Eds.), Training for a rapidly changing workplace: applications of psychological research (pp.281-302). Washington DC: American Psychological Association.

Bandura, A. (1986). Social foundations of thought and action: A social cognitive theory. Englewood Cliffs, NJ: Prentice-Hall. 
Bandura, A. (2001). Modeling. In E. Craighead \& C. Nemeroff (Eds.), The corsini encyclopedia of psychology and behavioral science (pp.967-968). John Wiley \& Sons.

Barron, B. (2004). Learning ecologies for technological fluency: Gender and experience differences. Journal of Educational Computing Research, 31(1), 1-36.

Carroll, J., \& Rosson, B. (1987). The paradox of the active user. In J. M. Carroll (Ed.), Interfacing thought: Cognitive aspects of human-computer interaction (pp.80-111). MIT Press, Bradford Books.

Compeau, D., \& Higgins, C. (1995). Application of social cognitive theory to training for computer skills. Information Systems Research, 6(2), 118-143.

Corrall, S. (2008). Information literacy strategy development in higher education: An exploratory study. International Journal of Information Management, 28, 26-37.

Davis, F. D., \& Yi, M.Y. (2004). Improving computer skill training: behavior modeling, symbolic mental rehearsal, and the role of knowledge structures. Journal of Applied Psychology, 89(3), 509-523.

de Souza, J.M.B., \& Dyson, M. (2008). Are animated demonstrations the clearest and most comfortable way to communicate on-screen instructions? Information Design Journal, 16(2), 107-124.

Despotakis, T., Palaigeorgiou, G., \& Siozos, P. (2003). Context-based autonomous monitoring module for web educational environments. In J. Jacko \& C. Stephanidis (Eds.), Human-computer interaction: Theory and practice (pp.911-916). CRC Press.

Despotakis, T., Palaigeorgiou, G., \& Tsoukalas, I. (2007). Students' attitudes towards animated demonstrations as computer learning tools. Journal of Educational Technology \& Society, 10(1), 196-205.

Educause Learning Initiative (2006). 7 things you should know about screencasting. Retrieved February 22, 2010 from http://www.educause.edu/ELI/7ThingsYouShouldKnowAboutScree/156815

Eisenberg, M., \& Fischer, G. (1993). Symposium: Learning on demand. Proceedings of the Fifteenth Annual Conference of the Cognitive Science Society, 180-186.

Ertelt, A. (2007). On-screen videos as an effective learning tool: The effect of instructional design variants and practice on learning achievements, retention, transfer, and motivation. Phd Dissertation, University of Freiburg, Germany. Retrieved February 22, 2010 from: http://www.freidok.unifreiburg.de/volltexte/3095/pdf/Dissertation_Ertelt_end.pdf

Ertelt, A., Renkl, A., \& Spada, H. (2006). Making a difference - Exploiting the full potential of instructionally designed on-screen videos. Proceedings of the International Conference on Learning Sciences, $154-160$.

Fu, W., \& Gray, W. (2004). Resolving the paradox of the active user: Stable suboptimal performance in interactive tasks. Cognitive Science, 28(6), 901-935.

Greer, R. D., Dudek-Singer, J., \& Gautreaux, G. (2006). Observational learning. International Journal of Psychology, 41(6), 486-499.

Grossman, T., Fitzmaurice, G., \& Attar, R. (2009). A survey of software learnability: Metrics, methodologies and guidelines. Proceedings of the 27th international Conference on Human Factors in Computing Systems (CHI), 649-658.

Gupta, S., \& Bostrom, R. P. (2006). End-user training methods: What we know, need to know. Proceedings of the 2006 ACM SIGMIS CPR conference on computer personnel research, 172-182.

Haas, S. W., Brown, R.T., Cao, L., \& Wilbur, J. D. (2005). Evaluation of the GovStat Statistical Interactive Glossary: Implications for just-in-time help. Proceedings of the 2005 National Conference on Digital Government Research, 291-292.

Harrison, S. M. (1995). A comparison of still, animated, or nonillustrated on-line help with written or spoken instructions in a graphical user interface. Proceedings of the SIGCHI conference on Human Factors in Computing Systems, 82-89. 
Höffler, T. N., \& Leutner, D. (2007). Instructional animation versus static pictures: A meta-analysis. Learning and Instruction, 17, 722-738.

Just, M., \& Carpenter, P. (1987). The psychology of reading and language comprehension. Boston, MA: Allyn \& Bacon.

Kalyuga, S., Ayres, P., Chandler, P., \& Sweller, J. (2003). The expertise reversal effect. Educational Psychologist, 38, 23-31.

Kerr, M. P., \& Payne, S. J. (1994). Learning to use a spreadsheet by doing and by watching. Interacting with Computers, 6(1), 3-22.

Kiesler, S., Zdaniuk, B., Lundmark, V., \& Kraut, R. (2000). Troubles with the Internet: The dynamics of help at home. Human Computer Interaction, 15, 323-351.

Kroski, E. (2009). That's infotainment: How to create your own screencasts. School Library Journal, 55(2), $40-42$.

Lazar, J., Jones, A., \& Shneiderman, B. (2006). Workplace user frustration with computers: An exploratory investigation of the causes and severity. Behaviour and Information Technology, 25(3), 239-251.

Lewis, D., \& Barron, A. (2009). Animated demonstrations: Evidence of improved performance efficiency and the worked example effect. Proceedings of HCI International 2009, 247-255.

Lipps, A. W., Trafton, J. G., \& Gray, W. D. (1998). Animation as documentation: A replication with reinterpretation. The 1998 Society for Technical Communication. Retrieved February 22, 2009: http://www.stc.org/confproceed/1998/PDFs/00006.PDF

Lowe, R. K. (2003). Animation and learning: Selective processing of information in dynamic graphics. Learning \& Instruction, 13, 157-176.

Margolis, H. (2005). Increasing struggling learner's self-efficacy: What tutors can do and say. Mentoring and Tutoring, 13(2), 221-238.

Mayer, R. E. (2005). Cognitive theory of multimedia learning. In R. E. Mayer (Ed.), The Cambridge handbook of multimedia learning (pp.31-48). Cambridge: Cambridge University Press.

Mayer, R. E., \& Moreno, R. (2003). Nine ways to reduce cognitive load in multimedia learning. Educational Psychologist, 38, 43-52.

Oud, J. (2009). Guidelines for effective online instruction using multimedia screencasts. Reference Services Review, 37(2), 164-177.

Paas, F., Renkl, A., \& Sweller, J. (2004). Cognitive load theory: Instructional implications of the interaction between information structures and cognitive architecture. Instructional Science, 32, 1-8.

Palmiter, S. (1993). The effectiveness of animated demonstrations for computer-based tasks: A summary, model and future research. Journal of Visual Languages and Computing, 4(1), 71-89.

Palmiter, S., \& Elkerton, J. (1991). An evaluation of animated demonstrations for learning computer-based tasks. Proceedings of the SIGCHI conference on Human Factors in Computing Systems, 257-263.

Palmiter, S., \& Elkerton, J. (1993). Animated demonstrations for learning procedural computer-based tasks. Human-Computer Interaction, 8(3), 192-216.

Pane, J. F., Corbett, A. T., \& John, B. E. (1996). Assessing dynamics in computer-based instruction. Proceedings of the SIGCHI conference on Human Factors in Computing Systems, 797-804.

Payne, S. J., Chesworth, L., \& Hill, E. (1992). Animated demonstrations for exploratory learners. Interacting with Computers, 4(1), 3-22.

Phelps, R., Hase, S., \& Ellis, A. (2005). Competency, capability, complexity and computers: Exploring a new model for conceptualizing end-user computer education. British Journal of Educational Technology, 36(1), 67-84. 
Plaisant, C., \& Shneiderman, B. (2005). Show Me! Guidelines for producing recorded demonstrations. IEEE Symposium on Visual Languages and Human-Centric Computing, 171-178.

Plass, J. L., Homer, B. D., \& Hayward, E. (2009). Design factors for educationally effective animations and simulations. Journal of Computing in Higher Education, 21(1), 31-61.

Rieman, J. (1996). A field study of exploratory learning strategies. ACM Transactions on ComputerHuman Interaction, 3(3), 189-218.

Shneiderman, B., \& Plaisant, C. (2005). Designing the user interface: Strategies for effective humancomputer interaction (4th ed.). Boston, MA: Addison-Wesley.

Spannagel, C., Girwidz, R., Lothe, H., Zendler, A., \& Schroeder, U. (2008). Animated demonstrations and training wheels interfaces in a complex learning environment. Interacting with Computers, 20, 97-111.

Schwan, S., \& Riempp, R. (2004). The cognitive benefits of interactive videos: Learning to tie nautical knots. Learning and Instruction, 14, 293-305.

Tversky, B., Morrison, J. B., \& Betrancourt, M. (2002). Animation: Can it facilitate. International Journal of Human-Computer Studies, 57(4), 247-262.

Van Merriënboer J. J. G., \& Sweller, J. (2005). Cognitive load theory and complex learning: Recent developments and future directions. Educational Psychology Review, 17, 147-177.

Waterson, P., \& O'Malley, C. (1992). Using animated demonstrations to teach graphics skills. Proceedings of the Conference on People and Computers VII, 463-474.

Wouters, P., Paas, F., \& van Merriënboer, J. J. G. (2008). How to optimize learning from animated models: A review of guidelines based on cognitive load. Review of Educational Research, 78(3), 645-675.

Yi, M.Y., \& Davis, F. D. (2001). Improving computer training effectiveness for decision technologies: Behavior modeling and retention enhancement. Decision Sciences, 32(3), 521-544.

Yi, M.Y., \& Davis, F. D. (2003). Developing and validating an observational learning model of computer software training and skill acquisition. Information Systems Research, 14, 146-169.

\section{Biographies}

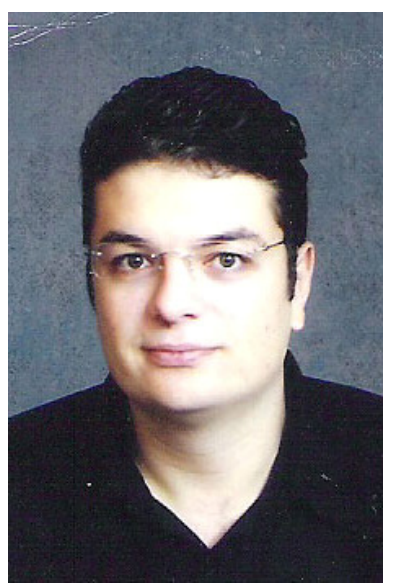

George E. Palaigeorgiou is researcher and adjunct lecturer in the Department of Computer \& Communication Engineering at the University of Thessaly, and in the Computer Science Department at Aristotle University of Thessaloniki, in Greece. He holds a PhD in StudentsComputers Interaction from the Computer Science Department at the Aristotle University of Thessaloniki and an M.B.A. from University of Macedonia, also in Greece. His publications include research articles in Journal of Computer Assisted Learning, Computers \& Education, British Journal of Educational Technology, Educational Technology \& Society etc. and his research interests include screencasting, participatory design, interaction design and Web 2.0. 


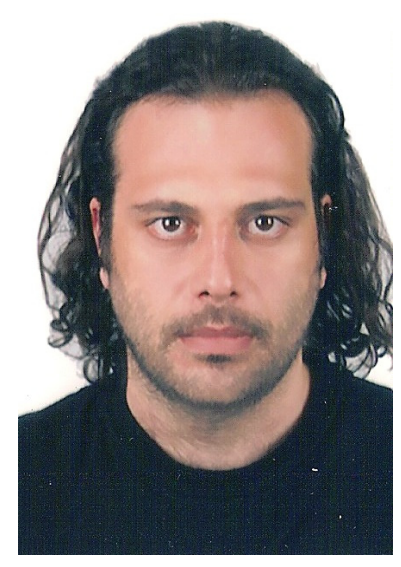

Theofanis Ch. Despotakis is a researcher and IT consultant with long experience in designing and developing internet applications. He is a partner of many software development companies in Greece (including Dotsoft Internet Applications S.A., Draxis Enviromental Technologies S.A., New-Media S.A.). His research interests include screencasting, intelligent tutoring systems, Web 2.0. and has several publications in scientific journals and international conferences concerning educational technology such as Computers \& Education, Educational Technology \& Society etc. 